\title{
Low durophagous predation on Toarcian (Early Jurassic) ammonoids in the northwestern Panthalassa shelf basin
}

\author{
Yusuke Takeda and Kazushige Tanabe \\ Acta Palaeontologica Polonica 60 (4), 2015: 781-794 doi:http://dx.doi.org/10.4202/app.00131.2014
}

Predatory shell breakage is known to occur occasionally on the ventrolateral portion of the body chamber in Mesozoic ammonoids. Here we report, for the first time, quantitative data of shell breakage in large ammonoid samples that were recovered from the lower Toarcian (Lower Jurassic) strata in the Toyora area, western Japan. The strata yielding the ammonoid samples consisted mostly of well-laminated, bituminous black shale that was deposited in an oxygen-depleted shelf basin of the northwestern Panthalassa, under the influence of the early Toarcian oceanic anoxic event. Among a total of 1305 specimens from 18 localities, apparent shell breakage was recognised in 35 specimens belonging to 7 genera, resulting in only a $2.7 \%$ frequency of occurrence relative to the total number of specimens. The breakage occurs mostly on the ventrolateral side of the body chamber with a complete shell aperture. This fact, as well as the low energy bottom condition suggested for the ammonoid-bearing shale, indicate that the shell breaks observed in the examined ammonoids were not produced by non-biological, post-mortem biostratinomical processes but were lethal injuries inflicted by nektonic predators such as reptiles, jawed fishes, coleoids, nautiloids, and carnivorous ammonoids with calcified rostral tips in their upper and lower jaws. Similar predatory shell breaks on the ventrolateral side of the body chamber have been found in contemporaneous ammonoid assemblages of the Tethys Realm, with a much higher frequency of occurrence than in the examined samples from the northwestern Panthalassa, suggesting a weaker durophagous predation pressure on ammonoids in the latter bioprovince.

Key words: Ammonoids, predation, ventral bite marks, Jurassic, Toarcian, Panthalassa.

Yusuke Takeda [ytakeda@um.u-tokyo.ac.jp], Department of Earth and Planetary Science, The University of Tokyo, 7-3-1, Hongo, Tokyo 113-0033, Japan; Kazushige Tanabe [tanabe@um.u-tokyo.ac.jp], Department of Historical Geology and Palaeontology, The University Museum, The University of Tokyo, 7-3-1, Hongo, Tokyo 113-0033, Japan. 
This is an open-access article distributed under the terms of the Creative Commons

Attribution License (for details please see creativecommons.org), which permits unrestricted use, distribution, and reproduction in any medium, provided the original author and source are credited.

FoF 